\title{
ARTICLE \\ Generation and analysis of spheroids from human primary skin myofibroblasts: an experimental system to study myofibroblasts deactivation
}

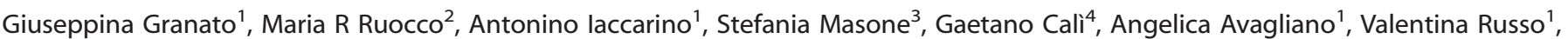
Claudio Bellevicine ${ }^{1}$, Gaetano Di Spigna ${ }^{5}$, Giuseppe Fiume ${ }^{6}$, Stefania Montagnani ${ }^{1}$ and Alessandro Arcucci ${ }^{1}$

Myofibroblasts are activated fibroblasts involved in tissue repair and cancer. They are characterized by de novo expression of $a$-smooth muscle actin ( $a$-SMA), immunoregulatory phenotype and paracrine interaction with normal and tumorigenic cells leading to cell proliferation. At the end of wound-healing myofibroblasts undergo apoptotic cell death, whereas in vitro-activated fibroblasts are also subjected to a programmed necrosis-like cell death, termed nemosis, associated with cyclooxygenase-2 (COX-2) expression induction and inflammatory response. Furthermore, myofibroblasts form clusters during wound healing, fibrotic states and tumorigenesis. In this study, we generated and analysed clusters such as spheroids from human primary cutaneous myofibroblasts, which represent a part of stromal microenvironment better than established cell lines. Therefore, we evaluated apoptotic or necrotic cell death, inflammation and activation markers during myofibroblasts clustering. The spheroids formation did not trigger apoptosis, necrotic cell death and COX-2 protein induction. The significant decrease of $a$-SMA in protein extracts of spheroids, the cytostatic effect exerted by spheroids conditioned medium on both normal and cancer cell lines and the absence of proliferation marker Ki-67 after $72 \mathrm{~h}$ of three-dimensional culture indicated that myofibroblasts have undergone a deactivation process within spheroids. The cells of spheroids reverted to adhesion growth preserved their proliferation capability and can reacquire a myofibroblastic phenotype. Moreover, the spontaneous formation of clusters on plastic and glass substrates suggests that aggregates formation could be a physiological feature of cutaneous myofibroblasts. This study represents an experimental model to analyse myofibroblasts deactivation and suggests that fibroblast clusters could be a cell reservoir regulating tissues turnover.

Cell Death Discovery (2017) 3, 17038; doi:10.1038/cddiscovery.2017.38; published online 17 July 2017

\section{INTRODUCTION}

Human fibroblasts represent a very heterogeneous cell population, that in adult body exhibits embryonic and functional diversities. ${ }^{1}$ In fact, although most fibroblasts are considered mesodermal cells, some reports showed that fibroblasts of neck skin are derived from neural crest tissue. ${ }^{2}$ Fibroblasts maintain the homoeostasis of the extracellular matrix (ECM), but can also acquire an immunoregulatory phenotype. ${ }^{2}$ In fact, it is known that activated fibroblasts produce large amounts of cyclooxygenase-2 (COX-2) and proinflammatory cytokines, although the extent of fibroblast activation depends on the tissue type. ${ }^{3}$ Activated fibroblasts in healing wounds, fibrotic or cancer tissue express de novo a-smooth muscle actin ( $a$-SMA), show increased levels of growth factors secretion and ECM-degrading proteases: these processes are regulated by inflammation and are involved in the differentiation of fibroblasts into myofibroblasts. ${ }^{2,4-6}$ At the end of wound healing, activated fibroblasts undergo apoptotic cell death, whereas in vitro fibroblasts endure also a programmed necrosis-like cell death, called nemosis. ${ }^{7,8}$ In particular, it is known that in vitro clusters of human dermal fibroblasts, named spheroids, are activated to produce massive amounts of COX-2, prostaglandins, proinflammatory cytokines and growth factors and thereby undergo nemosis associated with spheroids decomposition. ${ }^{8}$ It is noteworthy that a recent study showed that nemosis is a reversible process. ${ }^{9}$

Activated fibroblasts in vivo form clusters during wound-healing process, idiopathic pulmonary fibrosis and hypertrophic scars. ${ }^{10,11}$ Moreover, a recent work demonstrated that fibroblasts form aggregates in the dermis at early stages of melanoma development, before metastasis formation, and that a paracrine communication between cancer cells and fibroblasts leads to fibroblasts activation. ${ }^{12}$

Hence, the spheroids from human primary myofibroblasts could mimic regulation processes associated with myofibroblasts and tissues turnover.

The aim of this work was to produce and analyse spheroids from human primary myofibroblasts from normal skin of neck, evaluating apoptotic and necrotic cell death, inflammation and activation markers.

Our study demonstrated that spheroids formation is not associated with apoptotic or necrotic programmed cell death and that myofibroblasts, during clustering, have undergone a deactivation process. This work could represent a new experimental model to study myofibroblasts deactivation, and suggests

\footnotetext{
${ }^{1}$ Department of Public Health, University of Naples Federico II, Naples 80131, Italy; ${ }^{2}$ Department of Molecular Medicine and Medical Biotechnology, University of Naples Federico II, Naples 80131, Italy; ${ }^{3}$ Department of Clinical Medicine and Surgery, University of Naples Federico II, Naples 80131 , Italy; ${ }^{4}$ IEOS Istituto di Endocrinologia e Oncologia Sperimentale 'G. Salvatore', National Council of Research, Naples 80131, Italy; ${ }^{5}$ Department of Translational Medical Sciences, University of Naples Federico II, Naples 80131 , Italy and ${ }^{6}$ Department of Experimental and Clinical Medicine, University of Catanzaro 'Magna Graecia', Viale Europa, Catanzaro 88100, Italy. 
an alternative process regulating the turnover of myofibroblasts and tissues.

\section{RESULTS}

Analysis and clustering of human primary cells from neck skin We first carried out the morphological analysis of cells obtained from normal neck skin and used to generate spheroids. To this aim, the presence of intermediate filaments and stress fibres was evaluated in monolayer cells by vimentin immunofluorescence and phalloidin staining analysis, respectively (Figure 1a). This investigation detected the presence of vimentin intermediate filaments and stress fibres that are cytoskeletal markers of protomyofibroblasts, the cell type representing the intermediate step during fibroblasts to myofibroblasts differentiation process. ${ }^{13}$ Hence, we formed spheroids by using hanging-drops and agarose-coated U-bottom well plates adapted methods. ${ }^{14} \mathrm{We}$ obtained multicellular aggregates $24 \mathrm{~h}$ after the seeding of fibroblasts drops into agarose-coated wells and spheroids only after $48 \mathrm{~h}$ (Figure $1 \mathrm{~b}$ ). The volume of spheroids during their maturation decreases after $96 \mathrm{~h}$, as indicated in Figure 1b legend. This little decrease is due to a compaction process: in fact, spheroids did not undergo a decomposition process over time. We have cultured spheroids up to $216 \mathrm{~h}$, as shown below.

Immunohistochemical analysis of paraffin-embedded sections of both cell-suspension drop at $\mathrm{Oh}$ and spheroids collected at different times showed in cell-suspension drop and all spheroids the presence of vimentin (Figure 2a), an intermediate filament protein that is expressed in cells from mesenchymal origin. ${ }^{15,16}$ Western blotting analysis (Figures $2 \mathrm{~b}$ and $\mathrm{c}$ ) confirmed immunohistochemical results and did not show significant differences of vimentin protein levels in fibroblasts monolayer and spheroids.

Terminal deoxynucleotidyl transferase-mediated nick endlabelling (TUNEL) assay for apoptosis detection

DNA fragmentation represents a characteristic hallmark of apoptosis and TUNEL can detect and assess apoptosis at single cell level, based on labelling of DNA strand breaks. ${ }^{17}$ Therefore, we performed TUNEL staining of sectioned spheroids to evaluate whether forcing adherent cells, such as fibroblasts, to grow as multicellular aggregates could trigger apoptotic cell death (Figure 3). This analysis evidenced a few nuclei positive for DNA strand breaks, which did not display a time-dependent increase. In particular, TUNEL staining of spheroids collected at different time points detected $2.3 \%, 1.6 \%, 0.47 \%$ and $0.22 \%$ of apoptotic cells at 24, 48, 72 and $96 \mathrm{~h}$, respectively. These results indicated that fibroblasts clustering is not associated with apoptotic cell death.

\section{Evaluation of cell death markers}

Haematoxylin and eosin staining was performed to evaluate the presence of necrosis areas and apoptotic cells. This analysis did not detect necrosis in spheroids collected and analysed at different time points (Figure 4a). Moreover, spheroids stained with haematoxylin and eosin show some karyorrhectic nuclei, characteristic of apoptotic cell death and presenting a timedependent decrease, indicated in Figure 4a legend. Therefore, haematoxylin and eosin staining of spheroids collected at different time points confirms the results of TUNEL assay. It is known that during necrosis loss of membrane integrity leads to cellular lactate dehydrogenase $(\mathrm{LDH})$ release; $^{8}$ hence, we measured, at indicated time points, LDH enzymatic activity in conditioned medium of fibroblasts monolayer or spheroids (Figure 4b). A comparable LDH activity was measured in conditioned medium of both monolayer and spheroid cultures. In particular, there is not a significant difference of LDH activity between conditioned medium of monolayer and spheroid a

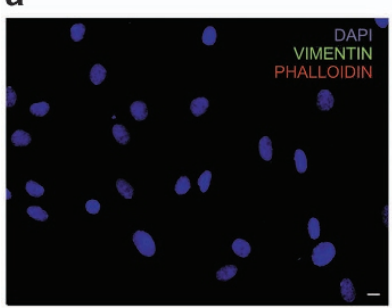

b
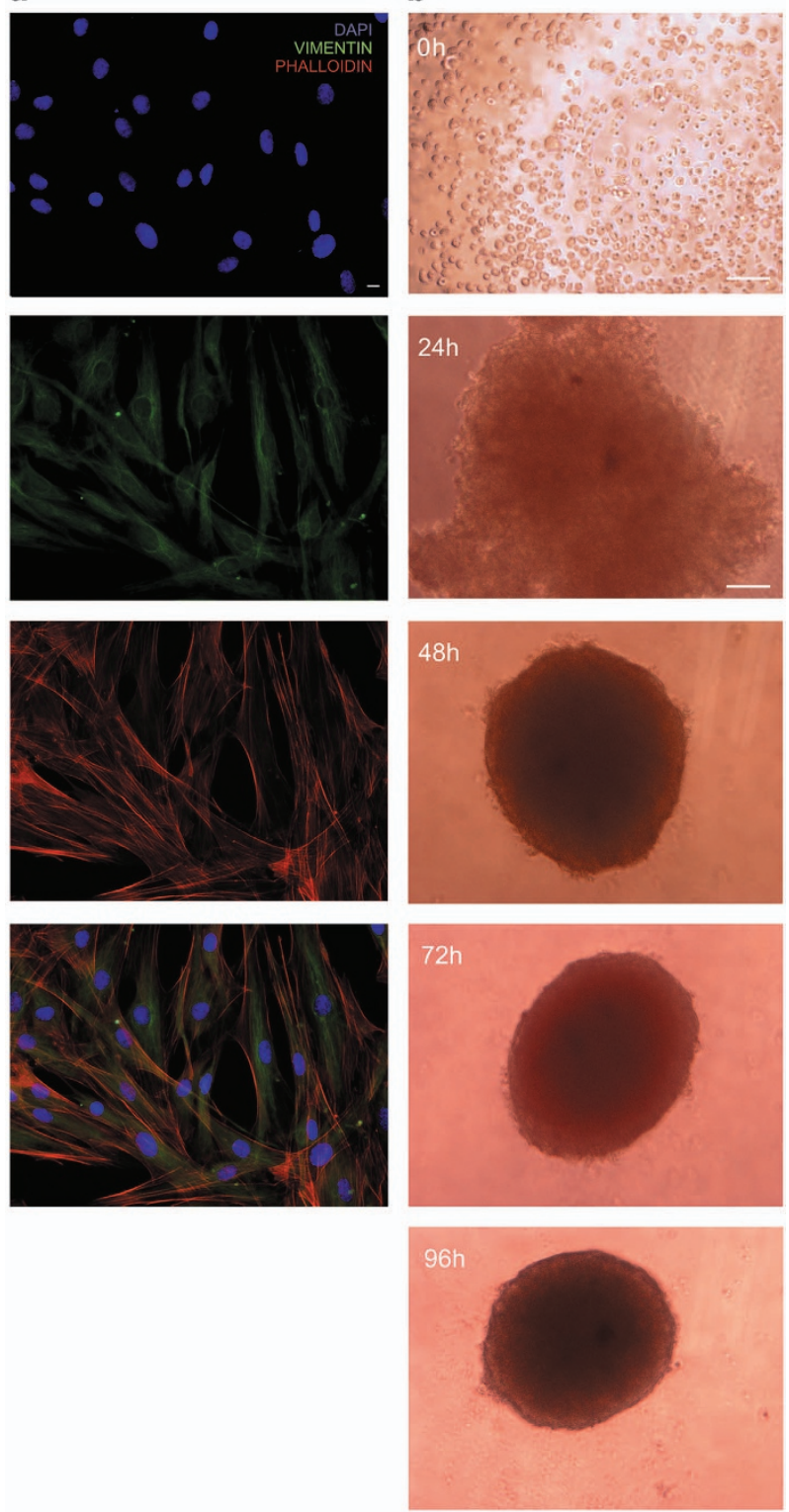

Figure 1. Analysis and clustering of human primary cells from neck skin. (a) Evaluation of vimentin immunofluorescence (green channel) and phalloidin staining (red channel) of primary cutaneous cells used to generate spheroids. DAPI (blue channel) was used to locate the nuclei of the cells (scale bar $=10 \mu \mathrm{m}$ ). Magnification $\times 40$. (b) Photographs of cell-suspension drop at $0 \mathrm{~h}$ and of the spheroid during its three-dimensional culture. Photographs have been taken through phase contrast microscope at the indicated times (scale bar, $100 \mu \mathrm{m})$. Magnification $\times 10$. Volumes of spheroids during their maturation at 48,72 and $96 \mathrm{~h}$ were $0.065 \mathrm{~mm}^{3} \pm 0.004$, $0.053 \mathrm{~mm}^{3} \pm 0.003$ and $0.043 \mathrm{~mm}^{3} \pm 0.003$, respectively. Data are reported as means of three independent experiments \pm S.E. $96 \mathrm{~h}$ versus $48 \mathrm{~h}$.

collected at indicated time points. Conversely, a significant increase of LDH activity in the conditioned medium of monolayers or spheroids was detected only after $96 \mathrm{~h}$, although more evident for myofibroblasts monolayer.

Inflammation and activation markers levels

To evaluate the levels of inflammation and activation markers during fibroblasts clustering, ${ }^{8,18}$ we analysed, by western blotting, 
a

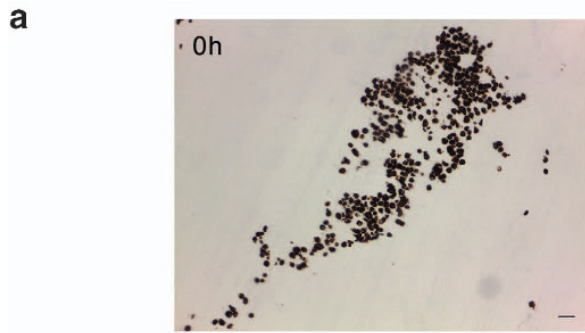

b

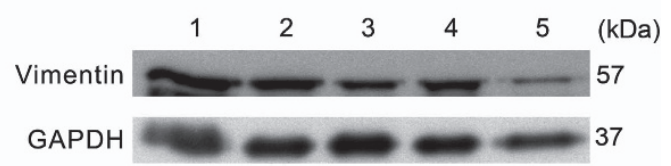

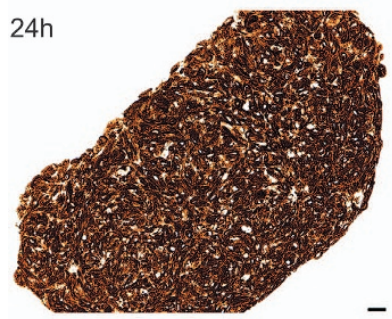

$72 \mathrm{~h}$

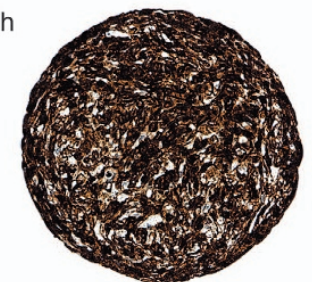

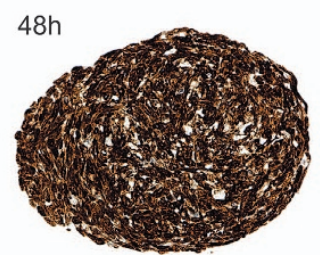

$96 \mathrm{~h}$

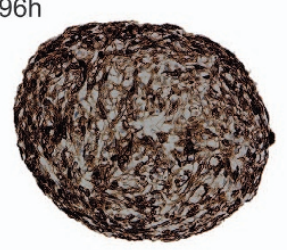

C

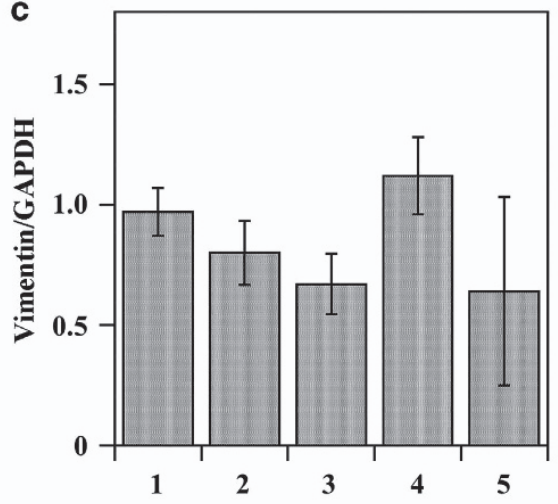

Figure 2. Analysis of vimentin. (a) Vimentin immunohistochemical analysis of paraffin-embedded sections of both cell-suspension drop at $0 \mathrm{~h}$ and spheroids collected at indicated time points (scale bar, $25 \mu \mathrm{m}$ ). $0 \mathrm{~h}$ cell-suspension drop: Magnification $\times 10$. Spheroids sections: Magnification $\times 20$. All images are representative of three independent experiments. (b) Vimentin western blotting analysis of fibroblasts monolayer (1), spheroids collected at $24 \mathrm{~h} \mathrm{(2),} 48 \mathrm{~h} \mathrm{(3),} 72 \mathrm{~h} \mathrm{(4)}$ and $96 \mathrm{~h} \mathrm{(5).} \mathrm{GAPDH} \mathrm{was} \mathrm{used} \mathrm{as} \mathrm{loading} \mathrm{control.} \mathrm{Representative} \mathrm{image} \mathrm{of} \mathrm{three}$ independent experiments is shown. (c) Densitometric analysis of vimentin protein levels. Fibroblasts monolayer (1), spheroids collected at $24 \mathrm{~h}(2), 48 \mathrm{~h}(3), 72 \mathrm{~h} \mathrm{(4)}$ and $96 \mathrm{~h}$ (5). Data are reported as means of three independent experiments \pm S.E.

COX-2 and $a$-SMA proteins in extracts of fibroblasts monolayer and spheroids (Figure 5a). This analysis showed that the fibroblasts monolayer express COX-2 protein and that spheroids do not present COX-2 overexpression induction. Moreover, there is a reduction of $a$-SMA levels in spheroids protein extracts, compared with monolayer extracts. In particular, the densitometric analysis demonstrated a time-dependent $a$-SMA decrease already significant at $48 \mathrm{~h}$ and more evident at 72 and $96 \mathrm{~h}$ (Figure 5b). The expression of $a$-SMA (Figure $5 \mathrm{a}$ ) together with the presence of vimentin intermediate filaments and stress fibres (Figure 1a) demonstrate that fibroblasts monolayer are myofibroblasts. $^{13}$ The dramatic decrease of the $a$-SMA in spheroids collected at different times suggests that myofibroblasts underwent a deactivation process during clusters formation: in fact, the $a$-SMA is a specific marker of fibroblasts to myofibroblasts differentiation. $^{13,19}$

It is known that activated fibroblasts enhance the proliferation of both normal and cancer cells, through paracrine interaction. ${ }^{20}$ Therefore, to further compare the activation state of myofibroblasts monolayer and spheroids, we analysed by MTT (3-(4,5dimethylthiazole-2-yl)-2,5-biphenyltetrazolium bromide) assay the effects of monolayers and spheroids conditioned medium on viability and cell proliferation of non-malignant $\mathrm{HaCat}$ and fibrosarcoma HT1080 cell lines (Figure 5c). ${ }^{20,21}$ This analysis showed that the viability of both cell lines incubated with spheroids conditioned medium was clearly lower than the one of cells treated with monolayer conditioned medium. These data further indicate that myofibroblasts underwent a deactivation process in spheroids.
Cell growth fraction in spheroids grown on agar or reverted to adhesion and monolayer growth

To evaluate the cell growth fraction in spheroids, we checked the presence of proliferation marker Ki- 67 by immunohistochemical analysis (Figure 6a). This investigation revealed the presence of about $10 \%$ and $6 \%$ positive nuclei for Ki-67 only in myofibroblasts cell suspension at $0 \mathrm{~h}$ and spheroids collected at $24 \mathrm{~h}$, respectively. In particular, $\mathrm{Ki}-67$, in all spheroids sections tested, does not localize in a restricted area but is evident in the centre as well as in the external areas of spheroids. Moreover, at $48 \mathrm{~h}$, we detected only one positive nucleus, while at 72 and $96 \mathrm{~h}$, we did not detect any positive nucleus for $\mathrm{Ki}-67$.

Spheroids grown on agar for 96 and $216 \mathrm{~h}$ were transferred on standard culture dishes to allow cell adhesion and spreading, and to analyse cells from spheroids during possible reversion to adhesion growth. This analysis demonstrated that spheroids can revert to adhesion growth (Figure $6 \mathrm{~b}$ ). Moreover, by a live cell-detection colorimetric assay, we evaluated cycle phases of cells outgrown from spheroids. This analysis showed that cells outgrowing from spheroids collected at $96 \mathrm{~h}$ were in G0/G1 (yellow pixels), S (green pixels) and G2/M (dark blue pixels) phases. Among all cell population derived from spheroids harvested at $216 \mathrm{~h}$, there are still evident growing cells, although the ones in S phase are rare.

Re-acquisition of myofibroblastic phenotype by cells of spheroids reverted to adhesion and monolayer growth

Confocal immunofluorescence analysis of cells outgrowing from spheroids reverted to adhesion growth, showed that cells of 
DAPI
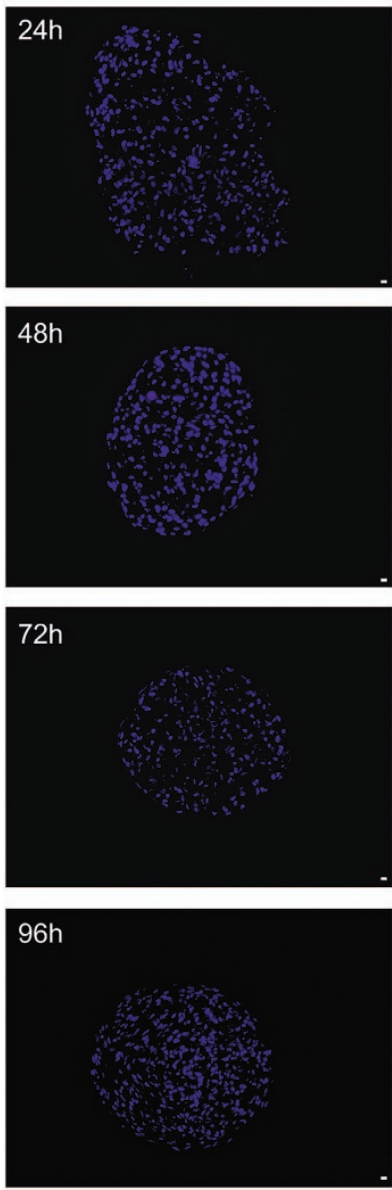

FITC
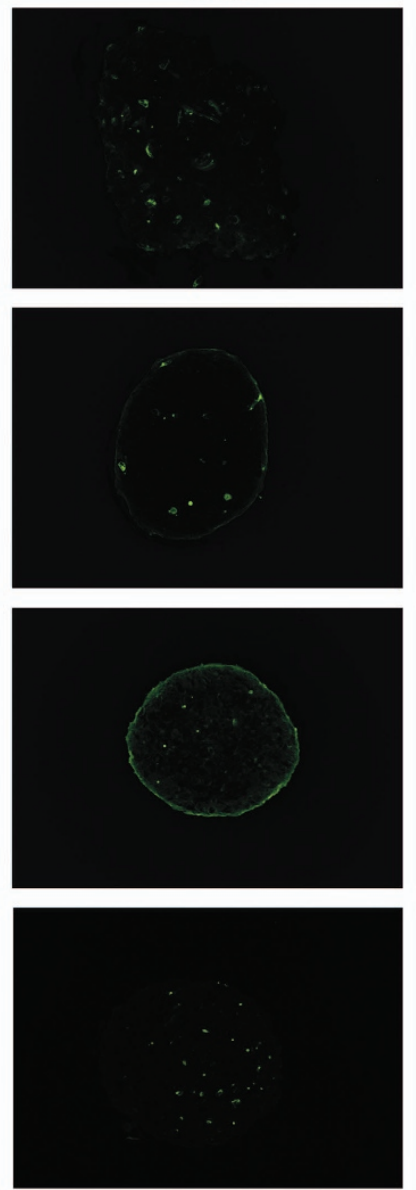

MERGE
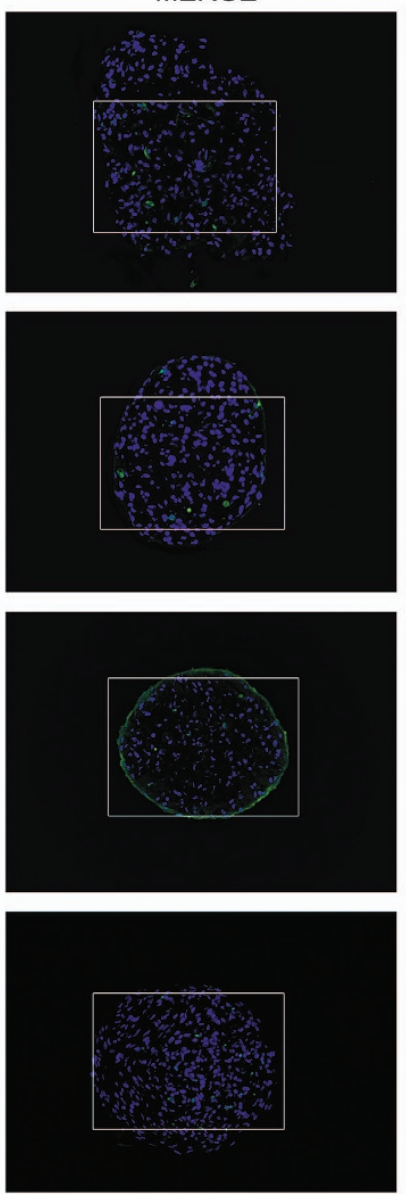
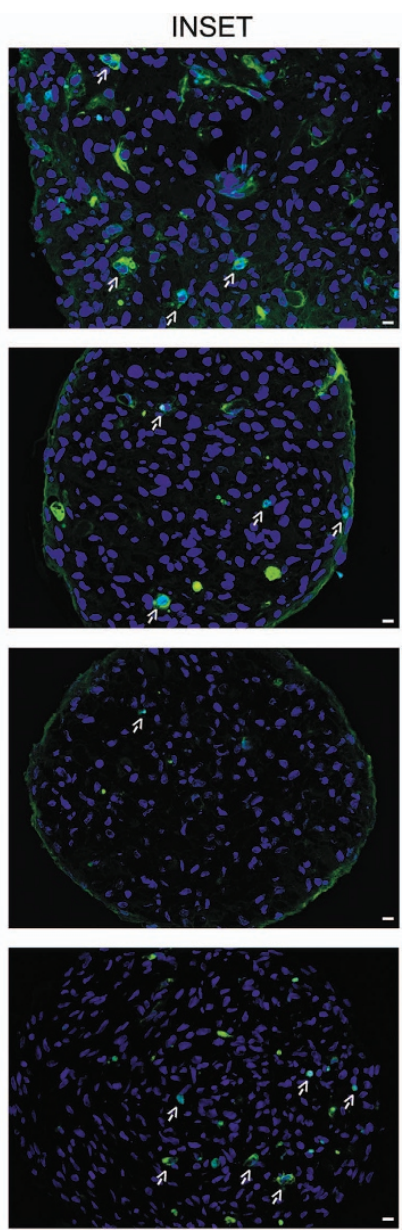

Figure 3. Identification of apoptotic cells. Terminal deoxynucleotidyl transferase-mediated nick end-labelling (TUNEL) assay for apoptosis detection in spheroids collected at different times (green channel). DAPI (blue channel) was used to locate the nuclei of fibroblasts (scale bar, $10 \mu \mathrm{m})$. Magnification $\times 10$. Inset: Magnification $\times 20$. Apoptotic nuclei in the insets are indicated by arrows (scale bar, $10 \mu \mathrm{m})$.

spheroids collected at $96 \mathrm{~h}$ present vimentin intermediate filaments and stress fibres (Figure 7a). On the other hand, cells of spheroids collected at $216 \mathrm{~h}$ display evident vimentin intermediate filaments but present fewer stress fibres than spheroids collected at $96 \mathrm{~h}$ (Figure $7 \mathrm{a}$ ). Furthermore, in spheroids collected at $96 \mathrm{~h}$, a vimentin and phalloidin staining colocalization is evident (Figure 7a). Western blotting and densitometric analysis of $a$-SMA levels showed that there is a dramatic and significant decrease of the protein in spheroids collected at $216 \mathrm{~h}$ and reverted to adhesion growth, compared to myofibroblasts monolayer (Figures $7 \mathrm{~b}$ and $\mathrm{c}$ ). Conversely, spheroids collected at $96 \mathrm{~h}$ and reverted to adhesion growth display $a$-SMA increased proteins level compared either with spheroids grown on agar and spheroids reverted to adhesion growth after $216 \mathrm{~h}$ of three-dimensional culture. Therefore, immunofluorescence and western blotting analysis indicate that deactivation process could be reversible for spheroids collected at $96 \mathrm{~h}$ because they present stress fibres and express $a$-SMA again. The spheroids collected at $216 \mathrm{~h}$, instead, present stress fibres less developed and display low $a$-SMA levels, comparable to spheroids grown only on agar.

Clusters and spheroids formed spontaneously on plastic or glass substrate

Surprisingly, we found that cutaneous myofibroblasts can form multicellular aggregates spontaneously, in absence of agar, both on plastic 12-well plates and on glass coverslips, 16 days after the seeding of cells (Figure 8). In particular, fibroblasts originated clusters and spheroids when the cell cultures were $100 \%$ confluent for several days. Furthermore, the outgrowth of cells from spheroid, reverted to adhesion growth, clearly demonstrates the vitality of cells inside spheroids (Figure 8d). Hence, these data suggest that the formation of clusters could be a physiological feature of these cells.

\section{DISCUSSION}

The fibroblast population of adult body shows functional differences associated with diversities in embryonic origins. ${ }^{1,2}$ In particular, some authors consider neck skin fibroblasts originated from neural crest tissue, although most fibroblasts are considered mesodermal cells. ${ }^{2}$

In our experimental system, cells used to form spheroids are myofibroblasts from normal neck skin. Fibroblasts in vitro differentiate to myofibroblasts when cultured on high stiffness substrate, such as plastic dishes, in the presence of TGF- $\beta .^{13}$ Furthermore, Santiago et al. ${ }^{22}$ showed that cardiac fibroblasts, cultured on rigid matrix represented by standard plastic plates, express $a$-SMA and differentiate to myofibroblasts. The myofibroblats used to generate spheroids express COX-2 protein, and this result is in agreement with a previous study showing that fetal bovine serum, present in fibroblasts monolayer and spheroids culture medium, can induce COX-2 expression and activate a transcriptional programme related to physiology of wound repair. $^{23}$ 
a
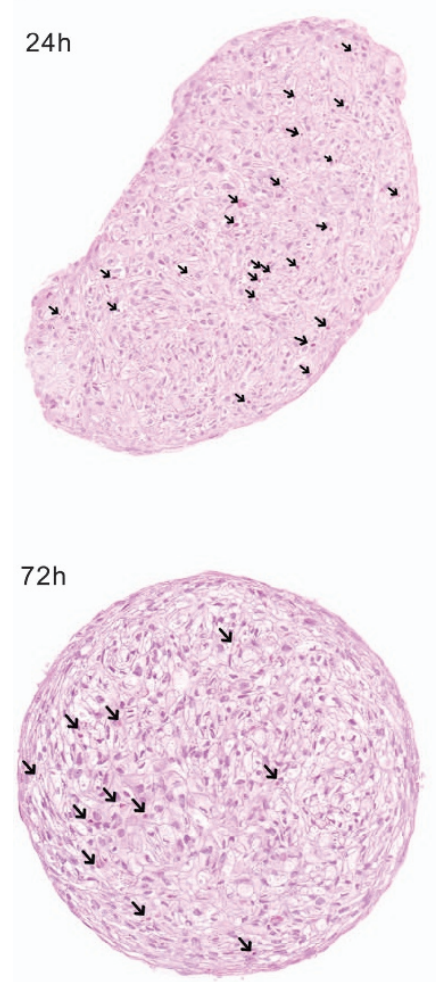

$48 \mathrm{~h}$

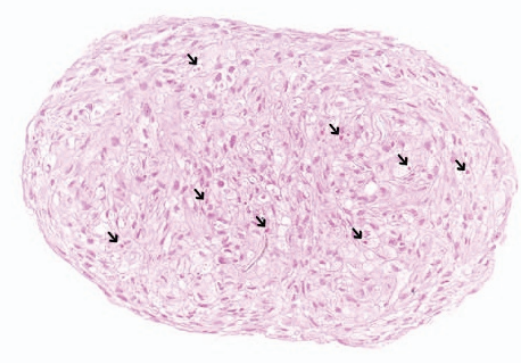

$96 \mathrm{~h}$

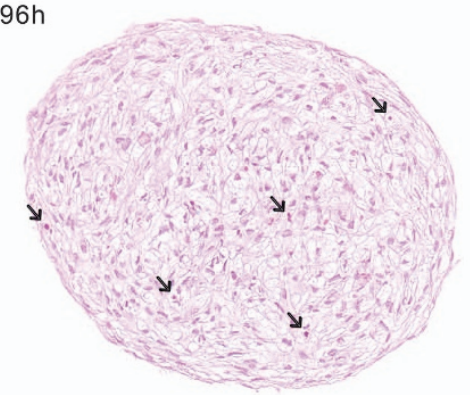

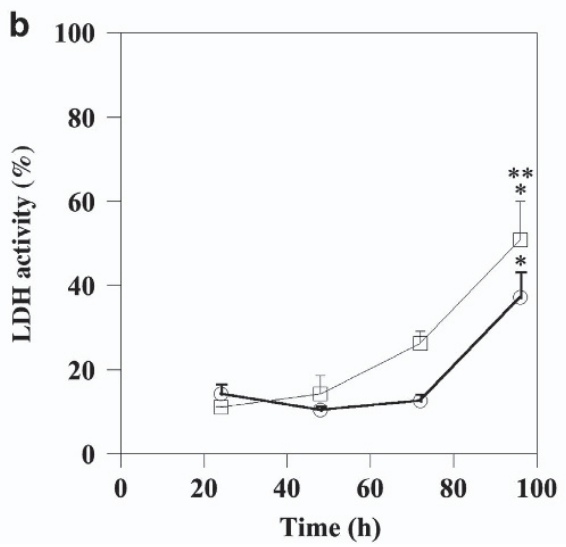

Figure 4. Cell death markers investigation. (a) Haematoxylin and eosin staining of paraffin-embedded sections of spheroids. The images of sections have been converted into high-resolution digital data (scale bar, $100 \mu \mathrm{m}$ ). Magnification $\times 200$. All images are representative of three independent experiments. The karyorrhectic nuclei, indicated by arrows, at $24 \mathrm{~h}, 48 \mathrm{~h}, 72 \mathrm{~h}$ and $96 \mathrm{~h}$ were: $22 \pm 2.1 ; 6.3 \pm 1.2 ; 6 \pm 2.5 ; 4 \pm 0.6$, respectively. Data are reported as means of three independent experiments \pm S.E. $P<0.005: 24 \mathrm{~h}$ versus $48 \mathrm{~h}$ and $72 \mathrm{~h}$. $P<0.001: 24 \mathrm{~h}$ versus $96 \mathrm{~h}$. (b) At selected time points, necrosis was assessed by measurement of LDH activity released in the conditioned medium of both monolayers (squares) and spheroids (circles). Data are means of three independent experiments \pm S.E. In conditioned medium of monolayers: $96 \mathrm{~h}$ versus $24 \mathrm{~h}{ }^{* *} P<0.005 ; 96 \mathrm{~h}$ versus $48 \mathrm{~h} * P<0.01$. In conditioned medium of spheroids: $96 \mathrm{~h}$ versus $24 \mathrm{~h}, 48 \mathrm{~h}$ and $72 \mathrm{~h} * P<0.01$.

This study demonstrated that human primary myofibroblasts from neck skin, when forced to grow as multicellular aggregates, do not undergo apoptosis or nemosis. Furthermore, vimentin immunohistochemical and western blotting analysis demonstrated that during spheroids formation fibroblasts save their mesenchymal origin. We showed that cell clustering does not lead to induction of COX-2 protein and spheroids decomposition, typical features of nemosis. ${ }^{8}$ COX-2 protein mediates tissue inflammation and tumorigenesis. ${ }^{24}$ In particular, as a result of tissue injury, fibroblasts migrate to the injured sites where they change to an activated and proinflammatory phenotype, associated with COX-2 expression. ${ }^{24}$ In our experimental system, the lack of COX-2 protein overexpression, during spheroids formation, suggests that myofibroblasts aggregation is not associated with inflammatory response.

Moreover, the significant decrease of $a$-SMA protein levels, the most widely used molecular marker of myofibroblasts, ${ }^{19,25}$ indicates that three-dimensional aggregation of myofibroblasts induced a deactivation process.

Analysis of reverted spheroids showed that this deactivation process is reversible for spheroids collected at $96 \mathrm{~h}$ and seems to be partially reversible for spheroids collected at $216 \mathrm{~h}$. In fact, spheroids collected at $216 \mathrm{~h}$ developed stress fibres less extensively than spheroids collected at $96 \mathrm{~h}$. Moreover, the significant difference of $a$-SMA levels between spheroids reverted to adhesion growth after 96 and $216 \mathrm{~h}$ of three-dimensional 
a

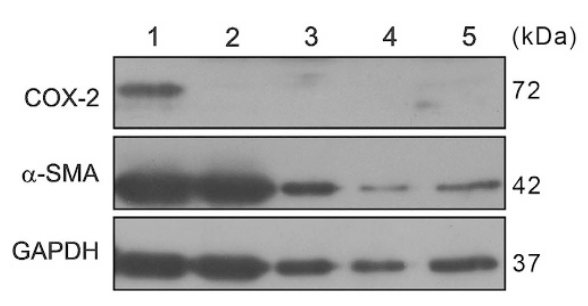

b

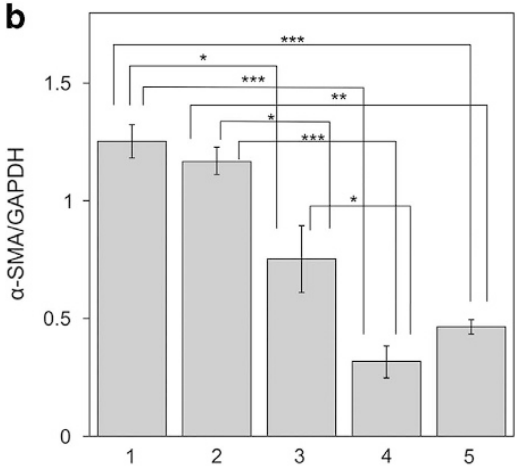

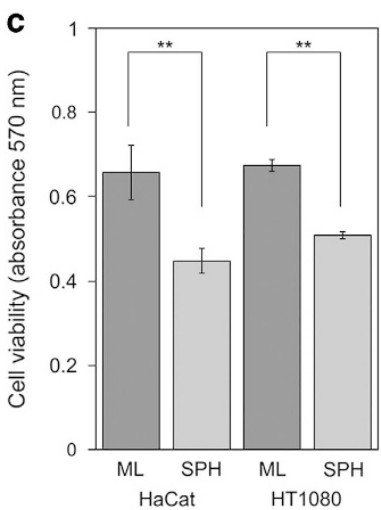

Figure 5. Inflammation and activation markers levels. (a) Western blotting analysis of COX-2 and $a$-SMA in protein extracts of fibroblasts monolayer (1), spheroids collected at $24 \mathrm{~h} \mathrm{(2),48} \mathrm{h} \mathrm{(3),} 72 \mathrm{~h}(4)$ and $96 \mathrm{~h}(5)$. GAPDH was used as loading control. Representative image of three independent experiments is shown. (b) Densitometric analysis of $a$-SMA protein levels. Fibroblasts monolayer (1), spheroids collected at $24 \mathrm{~h}$ (2), $48 \mathrm{~h}(3), 72 \mathrm{~h}(4)$ and $96 \mathrm{~h}(5)$. Data are reported as means of three independent experiments \pm S.E. ${ }^{*} P<0.05,{ }^{* *} P<0.005,{ }^{* * *} P<0.0005$. (c) Effect of conditioned medium of fibroblasts monolayer (ML) and spheroids (SPH) on normal (HaCat) and cancer (HT1080) cells. The cells were grown for $48 \mathrm{~h}$ with conditioned medium and cell viability was evaluated by MTT assay. Data are means of three independent experiments \pm S.E. ${ }^{* *} P<0.0001$.

culture, confirms and explains the immunofluorescence analysis. Therefore, the morphological and molecular phenotype of spheroids collected at $216 \mathrm{~h}$ resembles proto-myofibroblasts phenotype. $^{13}$

Vimentin and phalloidin staining co-localization detected only in spheroids collected at $96 \mathrm{~h}$ is explained by their higher phalloidin staining, compared with spheroids collected at $216 \mathrm{~h}$, and it is in agreement with previous studies showing that stress fibres contain vimentin and that actin and vimentin filaments can interact directly. ${ }^{26,27}$

The deactivation of myofibroblasts during clusters formation is confirmed by MTT assay. Previous study demonstrated that conditioned medium of activated fibroblasts within spheroids triggers the proliferation of nontumorigenic and tumorigenic cell lines. ${ }^{20}$ Conversely, in our experimental system, the cytostatic effect exerted by conditioned medium of spheroids on normal HaCat and metastatic HT1080 cell lines is evident. Paracrine epithelial-mesenchymal cell interactions have an important role in both tissue repair and cancer progression, through increased secretion of growth factors that support the proliferation of normal and tumorigenic cells. ${ }^{3,4,19,20,28}$ Our results, instead, indicate that the spheroids from primary cutaneous myofibroblasts do not resemble stromal microenvironment typical of wound healing and cancer.

Moreover, the deactivation of myofibroblasts inside spheroids is also supported by $\mathrm{Ki}-67$ immunohistochemical analysis showing that in spheroids collected at 72 and $96 \mathrm{~h}$ there are no positive nuclei for Ki-67 and all the cells are in $\mathrm{G}_{0}$ cycle phase: in fact, it is known that Ki-67 expression is associated with cell cycle progression. ${ }^{29}$ The immunohistochemical evaluation of Ki-67 and the $a$-SMA western blotting analysis of spheroids suggests that myofibroblasts deactivation is a step by step process.

However, colorimetric evaluation of cycle phases of cells from spheroids reverted to adhesion growth demonstrated that fibroblasts keep their proliferation capability within spheroids.

For many years, it was supposed that myofibroblasts could not revert to inactivated fibroblasts and myofibroblasts were considered cells terminally differentiated. In particular, at the end of wound healing, myofibroblasts undergo programmed cell death and to date it is not clear whether they can acquire a stable inactivated phenotype in vivo.,30,31 It is becoming evident that myofibroblasts can revert to a non-activated phenotype. ${ }^{32}$ In fact, it has been shown that murine myofibroblasts, originated from hepatic stellate cells, could revert to inactivated phenotype during regression of liver fibrosis: these deactivated cells can be rapidly reactivated into myofibroblasts in response to fibrogenic stimuli. ${ }^{33}$

Our report shows that forcing myofibroblasts to grown as multicellular aggregates induces myofibroblasts deactivation, and suggests an alternative process regulating the turnover of myofibroblasts. It is noteworthy that we have observed that primary cutaneous myofibroblasts are able to form spheroids spontaneously on high stiffness substrates represented by plastic or glass. It will be interesting to analyse these spontaneous spheroids and evaluate differences and resemblances with spheroids generated on agar.

The growth of fibroblasts as spheroids can be associated with conditions where fibroblasts lose their contact to connective tissue. In particular, fibroblasts can lose their contacts to ECM during inflammation, wound healing and cancer. In fact, in these 
situations several proteases, destroying ECM structure, liberate fibroblasts from ECM and trigger fibroblasts clusters formation. ${ }^{9}$

Moreover, another work detected fibroblasts aggregates in the dermis at early stages of melanoma development, before metastasis formation and showed a paracrine communication between cancer cells and fibroblasts. ${ }^{12}$

In conclusion, this study demonstrated that spheroids from human cutaneous primary myofibroblasts can be maintained in culture and that clusters formation does not trigger programmed cell death, but could represent a reservoir of fibroblasts. Our work

a
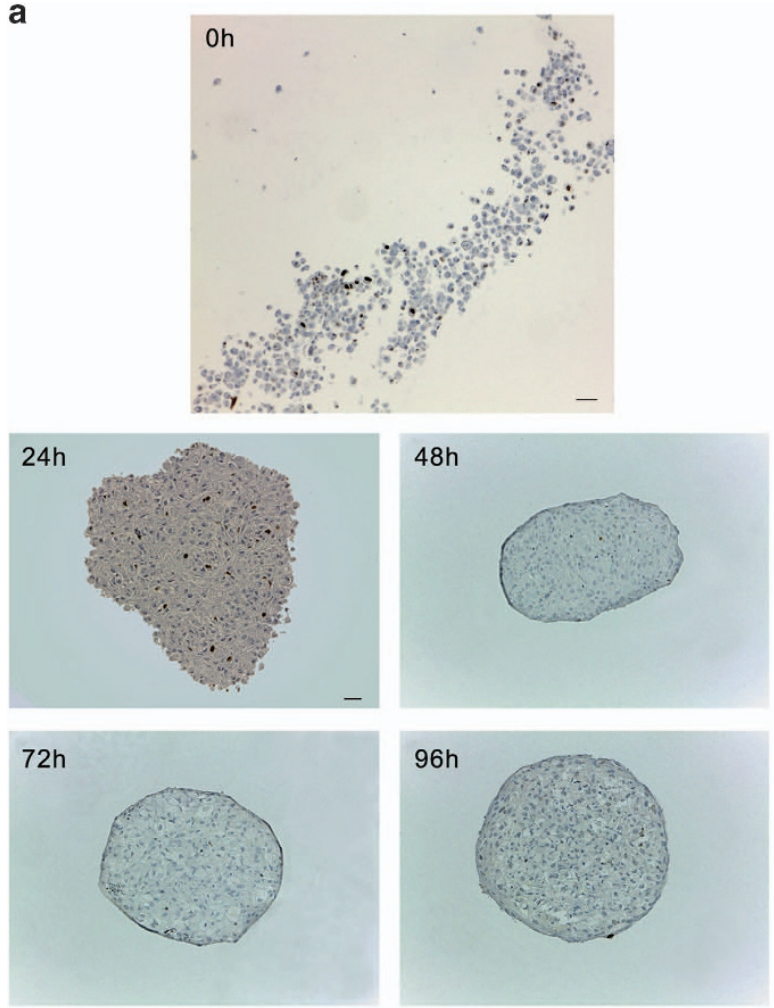

b
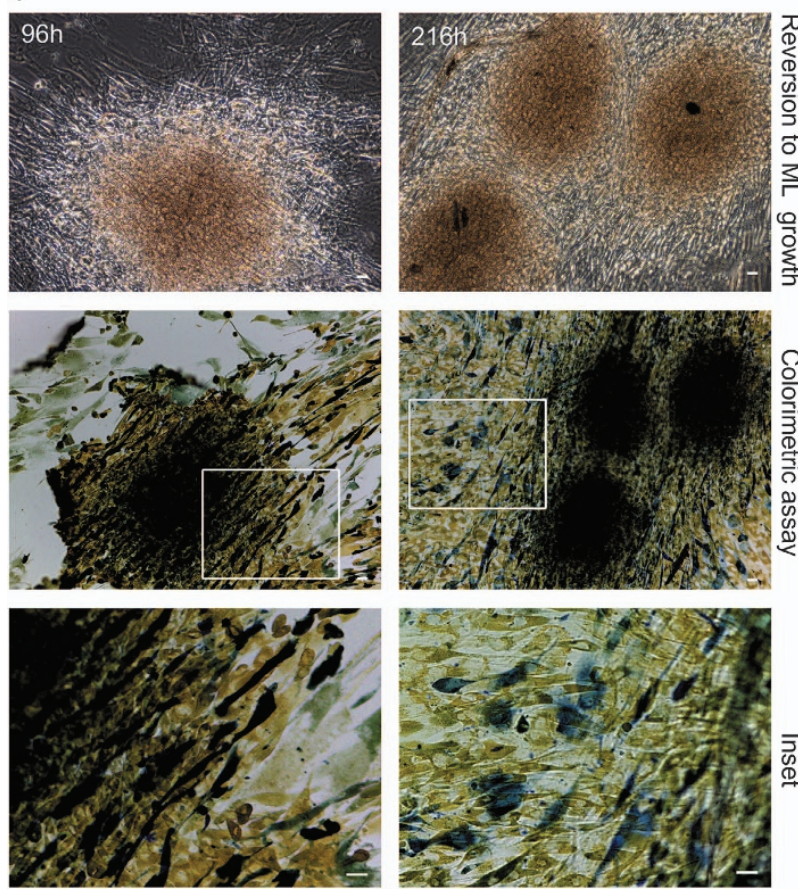

highlights new aspects about myofibroblasts turnover and could contribute to better understating the interaction between stroma and both normal and cancer cells.

\section{MATERIALS AND METHODS}

Cutaneous tissues

Normal skin specimens were obtained from donors ( $n=7$, females, mean age $50 \pm 2.5$ ) who had undergone neck surgery for benign pathologies. Patients with metabolic and connective tissue diseases were excluded. The investigation conforms to the principles outlined in the Declaration of Helsinki ${ }^{34}$ and informed consent was obtained from all the patients. The study reported in the manuscript has received the approval from the Ethic Committee of the University of Naples Federico II (Comitato Etico Università Federico II). The assigned protocol number of the study is 172/16.

\section{Cell cultures}

Cutaneous fibroblasts were obtained as follows: surgical fragments were cut and after repeated PBS washing, were plated and cultured in Dulbecco's minimal essential medium (DMEM; Sigma-Aldrich, Saint Louis, MO, USA) containing $200 \mathrm{mM}$ L-glutamine, penicillin $(100 \mathrm{mg} / \mathrm{ml})$, streptomycin $(100 \mathrm{mg} / \mathrm{ml})$ and $10 \% \mathrm{FBS}(\mathrm{GIBCO}$, Grand Island, NY, USA). The plates were incubated at $37{ }^{\circ} \mathrm{C}$ in the presence of $5 \% \mathrm{CO}_{2}$ and the medium was removed every 3 days. The outgrowth of fibroblasts from surgical fragments was observed after 1 week. When fibroblasts were $75 \%$ confluent, surgical fragments were removed and the cells were detached with $0.25 \%$ trypsin-EDTA and replated. All the experiments were performed only with cells from early passage $(<8)$.

Human keratinocyte (HaCat) and human metastatic fibrosarcoma cell lines (HT1080) were kindly provided by CEINGE (Naples, Italy).

The cells and spheroids were observed with a phase contrast microscope Olympus (Tokyo, Japan, Asia) CKX41 model; the images were acquired with a camera connected to the microscope by means Cell-A software.

All other chemicals were of analytical grade and were purchased from Sigma-Aldrich.

\section{Immunofluorescence analysis}

Morphological analysis of fibroblasts was performed by plating the cells on glass coverslips, fixing with $4 \%$ paraformaldehyde, permeabilizing with $0.1 \%$ Triton X-100 and blocking in donkey serum (Millipore, Billerica, MA, USA), diluted $1: 10$ in $1 \times$ PBS, for $30 \mathrm{~min}$ at room temperature. Glass coverslips were incubated with a mouse monoclonal anti-vimentin primary antibody (Sigma-Aldrich), diluted $1: 50$, for $1 \mathrm{~h}$ at $37^{\circ} \mathrm{C}$, and then washed three times with $1 \times$ PBS and subsequently incubated with a FITC donkey anti-mouse secondary antibody (Jackson ImmunoResearch, Suffolk, UK) diluted $1: 50$ and phalloidin-TRITC (Sigma-Aldrich) diluted $1: 100$, for $1 \mathrm{~h}$ at $37^{\circ} \mathrm{C}$. The cell nuclei were labelled with DAPI (Vector Laboratories, Inc, Burlingame, CA, USA). Glass coverslips mounting was done in Vectashield (Vector Laboratories). The images were taken with digital camera connected to the microscope (Leica DFC345FX, Leica Microsystems, Wetzlar, Germany) and then merged with the software Leica Application Suite 3.6.

Figure 6. Evaluation of the cell growth fraction in spheroids grown on agar or reverted to adhesion and monolayer growth (ML). (a) Ki-67 immunohistochemical analysis of paraffin-embedded sections of myofibroblasts cell suspension at $\mathrm{Oh}$ and spheroids collected at indicated time points (scale bar, $25 \mu \mathrm{m}$ ). Myofibroblasts cell suspension at $0 \mathrm{~h}$ : Magnification $\times 10$. Spheroids: magnification $\times 20$. (b) Spheroids collected at $96 \mathrm{~h}$ and $216 \mathrm{~h}$ were transferred to plastic dishes and maintained in culture for 12 days before to be processed. Images represent spheroids reverted to adhesion growth, photographed by phase contrast microscope and then stained with a live cell-detection kit to monitor cell cycle. Yellow pixels represent cells in G0/G1 phase, green pixels represent cells in $S$ phase and dark blue pixels represent cells in G2/M phase (scale bar, $25 \mu \mathrm{m}$ ). Magnification $\times 10$. Inset: Magnification $\times 20$ (scale bar, $25 \mu \mathrm{m}$ ). The images are representative of three independent experiments. 
a
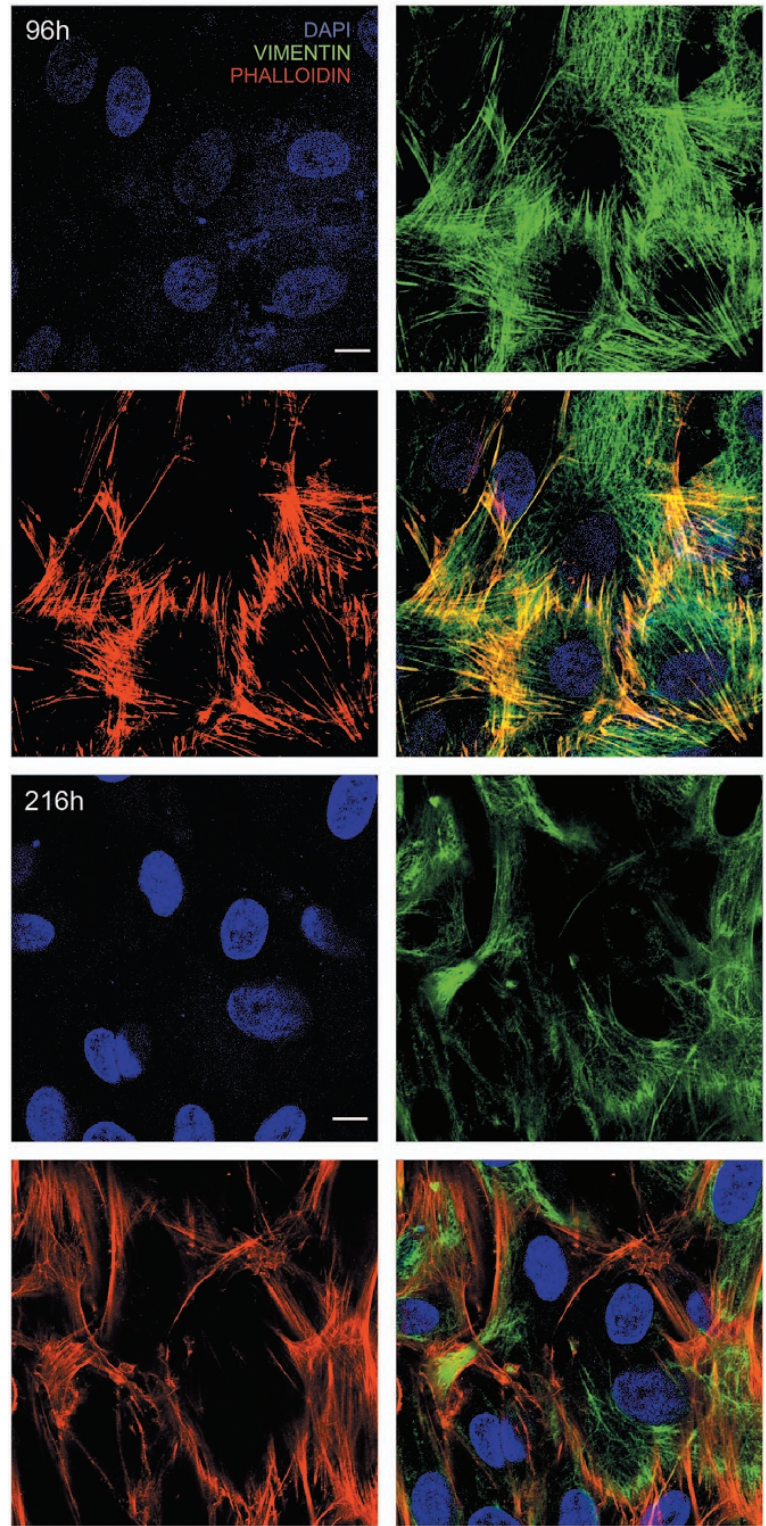

b
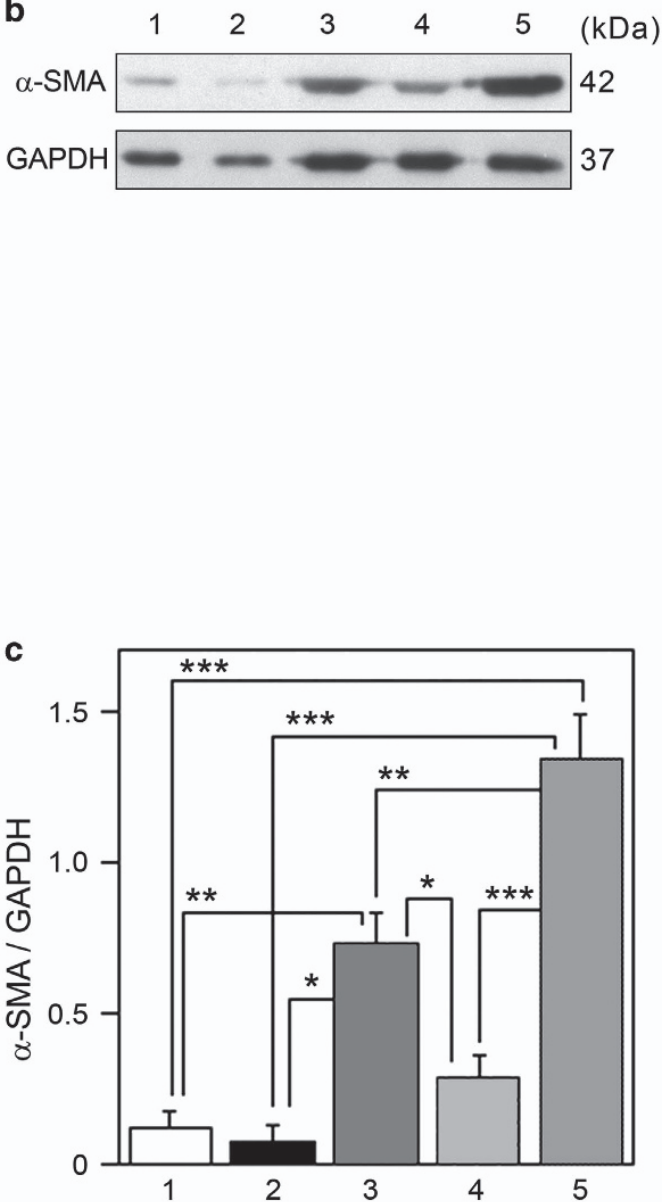

Figure 7. Spheroids collected at $96 \mathrm{~h}$ and $216 \mathrm{~h}$ were transferred to glass coverslips or plastic dishes, maintained in culture for 12 days and analysed. (a) Confocal fluorescence analysis of vimentin immunostaining (green channel) and phalloidin staining (red channel). DAPI (blue channel) was used to locate the nuclei (scale bar, $10 \mu \mathrm{m})$. The images are representative of three independent experiments. (b) Western

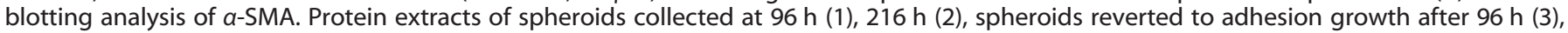
$216 \mathrm{~h} \mathrm{(4)} \mathrm{of} \mathrm{three-dimensional} \mathrm{culture} \mathrm{and} \mathrm{myofibroblasts} \mathrm{monolayer} \mathrm{(5).} \mathrm{GAPDH} \mathrm{was} \mathrm{used} \mathrm{as} \mathrm{loading} \mathrm{control.} \mathrm{Representative} \mathrm{image} \mathrm{of} \mathrm{three}$ independent experiments is shown. (c) Densitometric analysis of $a$-SMA protein levels. Spheroids collected at $96 \mathrm{~h}$ (1), $216 \mathrm{~h} \mathrm{(2),} \mathrm{spheroids}$ reverted to adhesion growth after $96 \mathrm{~h}$ (3), $216 \mathrm{~h}$ (4) of three-dimensional culture and myofibroblasts monolayer (5). Data are reported as mean \pm S.E. ${ }^{*} P<0.05,{ }^{* *} P<0.01,{ }^{* * *} P<0.0001$

Spheroids reverted to monolayer growth, previously fixed with $4 \%$ paraformaldehyde, were washed twice in $50 \mathrm{mM} \mathrm{NH}_{4} \mathrm{Cl}$, permeabilized for 5 min with $0.2 \%$ Triton X-100 as reported by Mascia et al. ${ }^{35}$

The nuclei were stained with DAPI. Immunofluorescence analysis was performed with a confocal laser scanning microscope LSM 700 (Zeiss, Gottingen, Germany) equipped with three lasers whose wavelengths are 405, 488 and $555 \mathrm{~nm}$. Fluorescence emission was revealed by 460-489 band pass filter for DAPI; 505-530 band pass filter for FITC and by 560-615 band pass filter for TRITC. Triple-staining immunofluorescence images were acquired separately in the green, red and UV channels at a resolution of $102 \times 1024$ pixels, with the confocal pinhole set to one Airy unit and then saved in TIFF format.

All other chemicals were of analytical grade and were purchased from Sigma-Aldrich.

\section{Generation and growth of spheroids}

To obtain spheroids, we used the previously described hanging-drops and agarose-coated U-bottom well plates adapted methods. ${ }^{14}$ To this aim, fibroblasts were detached from culture dishes by trypsin and $20 \mu \mathrm{l}$ of cell-suspension drop, containing $1 \times 10^{4}$ cells, were put on the lids of 96-well plates, containing $100 \mu \mathrm{l}$ of $1 \times$ PBS to avoid culture medium evaporation. After $12 \mathrm{~h}$ of incubation at $37^{\circ} \mathrm{C}$, the drops were transferred to U-bottom 96-well plates, containing $80 \mu \mathrm{l}$ of complete DMEM, and previously coated with $1 \%$ agarose (Applichem, Gatersleben, SaxonyAnhalt, Germany) in $1 \times$ PBS to avoid cell plate adhesion. Spontaneous spheroids were originated by plating $5 \times 10^{4}$ cells onto bottom of 12 -well plates or on glass coverslips and maintained in culture for several days. In particular, after 16 days, in many wells of plates, clusters and spheroids were evident. 
a

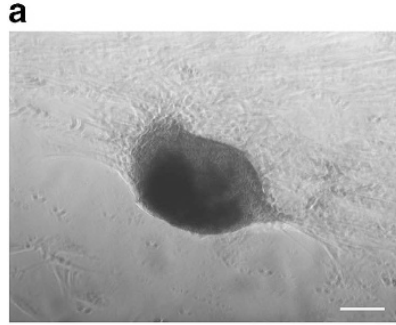

C

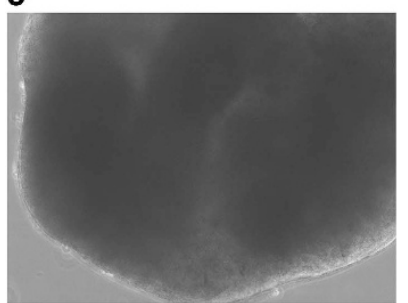

b

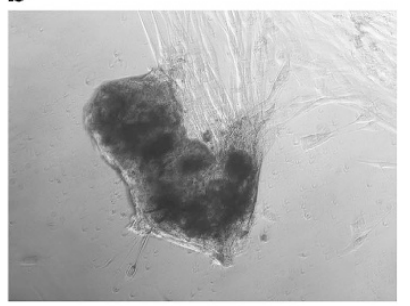

d

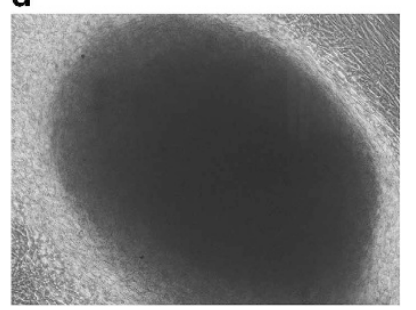

Figure 8. Clusters and spheroids formed spontaneously, without using hanging-drops and agarose-coated U-bottom well plates methods. (a and $\mathbf{b})$ Clusters formed on the bottom of plastic 12-well plates. (c and d) Spheroid formed on glass coverslip and reverted to adhesion growth (scale bar, $100 \mu \mathrm{m}$ ). Magnification $\times 10$.

The volumes of spheroids were calculated as previously described. ${ }^{14}$

The detection of cycle phases of cells from spheroids reverted to adhesion growth was performed, according to the manufacturer's protocol, through Cell-Clock Mammalian Cell Cycle Assay (Biocolor, Antrim, UK).

\section{Immunohistochemistry}

Each spheroid was fixed in 10\% neutral buffered formalin and embedded in paraffin (Bio-Optica Milano SpA, Milan, Italy), then sliced into serial $4 \mu \mathrm{m}$ thick sections and placed on poly-L-lysine coated glass slides (MenzelGlaser, Brunswick, Germany). The slides were deparaffinized, rehydrated and immersed in $10 \mathrm{mM}$ citric acid pH 6 (Sigma-Aldrich), in a microwave oven (VWR International PBI Srl, Milan, Italy) for three cycles of 5 min at 650 Watt, to exclude epitope masking owing to fixation. Spheroids sections were haematoxylin and eosin stained for necrosis and apoptosis analysis. Therefore, these sections, on glass slides, were converted into highresolution digital data through NanoZoomer-2.0RS digital scanner (Hamamatsu, Tokyo, Japan, Asia). The preparation of paraffin-embedded cell suspensions were performed by using Shandon Cytoblock Cell Block Preparation System (Thermo Scientific, Rockford, IL, USA) according to the manufacturer's protocol.

Other sections were immunostained with primary antibodies against Vimentin or Ki-67 (Ventana Medical Systems, Tucson, AZ, USA) detected by ULTRA View UNIVERSAL DAB DETECTION KIT (Ventana Medical Systems), according to the manufacturer's protocol. Microscopy analysis was performed with a Leica DMLB microscope (Leica Microsystems). The images were taken in bright field with a digital camera (Leica DC200; Leica Microsystems) connected to the microscope.

\section{TUNEL and LDH assays}

TUNEL staining was performed on spheroids sections, previously deparaffinized twice in xylene and rehydrated in graded series of ethanol, using ApopTag Plus Fluorescein In Situ Apoptosis Detection Kit (Millipore), according to the manufacturer's protocol.

To perform LDH enzymatic assay, $1 \times 10^{4}$ cutaneous myofibroblasts/well were grown as monolayer or spheroid cultures and, at selected time points, cytotoxicity was evaluated by measurement of LDH activity in the culture medium. Briefly, various aliquots of cell incubation medium were added to $1 \mathrm{ml}$ reaction mixture containing $0.1 \mathrm{M}$ Tris- $\mathrm{HCl}, \mathrm{pH} 7.5,125 \mu \mathrm{M}$ $\mathrm{NADH}$. The reaction started with the addition of $600 \mu \mathrm{M}$ sodium pyruvate followed by the decrease in absorbance at $340 \mathrm{~nm}$. The results were normalized respect to $100 \%$ death caused by various freezing and thawing of fibroblasts.

All other chemicals were of analytical grade and were purchased from Sigma-Aldrich.
Total cell lysates and western blotting analysis

Monolayer cells and spheroids, at indicated time points, were collected, washed with PBS, lysed in ice-cold modified RIPA buffer containing $50 \mathrm{mM}$ Tris- $\mathrm{HCl}, \mathrm{pH} 7.4,150 \mathrm{mM} \mathrm{NaCl}, 1 \%$ Nonidet P-40, $0.25 \%$ sodium deoxycholate, $1 \mathrm{mM} \mathrm{Na}_{3} \mathrm{VO}_{4}$ and $1 \mathrm{mM} \mathrm{NaF}$ supplemented with Protease Inhibitor Cocktails (Roche Diagnostics Corporation, Mannheim, Germany) and incubated for $30 \mathrm{~min}$ on ice. The supernatant, obtained after centrifugation at $12000 \mathrm{~g}$ for $20 \mathrm{~min}$ at $4{ }^{\circ} \mathrm{C}$, constituted total protein extract. Protein concentration was determined by Bradford's method, using bovine serum albumin as calibrator. ${ }^{36}$ Western blotting analysis was performed with equal amounts of total protein extracts $(20 \mu \mathrm{g})$. Briefly, protein samples were dissolved in SDS-reducing loading buffer, run on a $10 \%$ SDS/PAGE at $120 \mathrm{~V}$ and then transferred to Immobilon P membrane (Millipore). The membranes were incubated overnight at $4{ }^{\circ} \mathrm{C}$ with the following primary antibodies: COX-2, a-SMA (Abcam, Cambridge, UK), Vimentin (Cell Signal Technology Inc., Danvers, MA, USA) and GAPDH (Cell Signal Technology) and then with horseradish peroxidase-linked specific secondary antibodies (Santa Cruz Biotechnology, Santa Cruz, CA, USA) at room temperature for $1 \mathrm{~h}$. The membranes were analysed by an enhanced chemiluminescence reaction, using Super Signal West Femto Maximum Sensitivity Substrate kit (Thermo Scientific) according to the manufacturer's instructions. The signals were visualized by autoradiography. The images were acquired by Epson Perfection 2480 Photo (Epson, Suwa, Japan) and densitometric analysis was performed using the Image J 1.48i version (Wayne Rasband National Institutes of Health, USA).

All other chemicals were of analytical grade and were purchased from Sigma-Aldrich.

\section{MTT assay}

To evaluate the effect of monolayers or spheroids conditioned medium on normal HaCaT and tumorigenic HT1080 cell lines, $1 \times 10^{4}$ cells/well were seeded on 96-well plates and let to grow for $24 \mathrm{~h}$. Then, the culture medium was removed and replaced with $100 \mu \mathrm{l}$ of conditioned medium from monolayers or spheroids, cultured for $72 \mathrm{~h}$. After $48 \mathrm{~h}$ of incubation, MTT cell viability assay was performed. Briefly, $10 \mu$ l of $12 \mathrm{mM}$ MTT solution was added to each well, incubated for $3 \mathrm{~h}$ at $37^{\circ} \mathrm{C}$ in the dark and then MTT formazan crystals were dissolved in $100 \mu$ l of solubilization solution $(0.01 \mathrm{M} \mathrm{HCl}$ in isopropanol). Cells number is correlated with the amount of MTT formazan formed, that was evaluated by measuring absorbance at $570 \mathrm{~nm}$, using Multiscan EX microplate reader (Thermo Labsystems, Vantaa, Finland).

All chemicals were of analytical grade and were purchased from SigmaAldrich.

\section{Statistical analysis}

Numerical data were reported in Kaleida Grafh 4.0 and analysed by Student's $t$-test; one-way ANOVA, with Bonferroni corrections, was used for multiple comparisons.

\section{ACKNOWLEDGEMENTS}

We acknowledge Professor Antonio Feliciello for his careful review of the manuscript and helpful discussion. This work was supported by a grant from P.O.R Campania FESR 2007-2013-O.0.2.1-CUPB25C13000280007.

\section{AUTHOR CONTRIBUTIONS}

GG performed experiments, analysed the data and prepared the figures; Al, GC, A Avagliano, VR and GF performed the experiments; CB and GDS analysed the data; S Masone analysed data and provided surgical cutaneous samples; MRR and S Montagnani planned study, designed the experiments, analysed data and supervised the manuscript; A Arcucci conceived and planned study, analysed data and wrote paper.

\section{COMPETING INTEREST}

The authors declare no conflict of interest. 


\section{REFERENCES}

1 Sriram G, Bigliardi PL, Bigliardi-Qi M. Fibroblast heterogeneity and its implications for engineering organotypic skin models in vitro. Eur J Cell Biol 2015; 94: 483-512.

2 Buckley CD, Pilling D, Lord JM, Akbar AN, Scheel-Toellner D, Salmon M. Fibroblasts regulate the switch from acute resolving to chronic persistent inflammation. Trends Immunol 2001; 22: 199-204.

3 Vaheri A, Enzerink A, Rasanen KP, Salmenperä P. Nemosis, a novel way of fibroblast activation, in inflammation and cancer. Exp Cell Res 2009; 315: 1633-1638.

4 Liu M, Xu J, Deng H. Tangled fibroblasts in tumor stroma interactions. Int J Cancer 2011; 129: 1795-1805.

5 Zhang Y, Cao HJ, Graf B, Meekins H, Smith TJ, Phipps RP. CD40 engagement upregulates cyclooxygenase-2 expression and prostaglandin E2 production in human lung fibroblasts. J Immunol 1998; 160: 1053-1057.

6 Desmoulière A, Guyot C, Gabbiani G. The stroma reaction myofibroblast: a key player in the control of tumor cell behavior. Int J Dev Biol 2004; 48: 509-517.

7 Öhlund D, Elyada E, Tuveson D. Fibroblast heterogeneity in the cancer wound. J Exp Med 2014; 211: 1503-1523.

8 Bizik J, Kankuri E, Ristimäki A, Taïeb A, Vapaatalo H, Lubitz W et al. Cell-cell contacts trigger programmed necrosis and induce cyclooxygenase-2 expression. Cell Death Differ 2004; 11: 183-195.

9 Salmenperä P, Karhemo PR, Räsänen K, Laakkonen P, Vaheri A. Fibroblast spheroids as a model to study sustained fibroblast quiescence and their crosstalk with tumor cells. Exp Cell Res 2016; 345: 17-24.

10 da Rocha-Azevedo B, Grinnell F. Fibroblast morphogenesis on 3D collagen matrices: the balance between cell clustering and cell migration. Exp Cell Res 2013; 319: 2440-2446.

11 Ehrlich HP, Desmoulière A, Diegelmann RF, Cohen IK, Compton CC, Garner WL et al. Morphological and immunochemical differences between keloid and hypertrophic scar. Am J Pathol 1994; 145: 105-113.

12 Dror S, Sander L, Schwartz H, Sheinboim D, Barzilai A, Dishon Y et al. Melanoma miRNA trafficking controls tumour primary niche formation. Nat Cell Biol 2016; 18: 1006-1017.

13 Tomasek JJ, Gabbiani G, Hinz B, Chaponnier C, Brown RA. Myofibroblasts and mechano-regulation of connective tissue remodelling. Nat Rev Mol Cell Biol 2002; 3: 349-363.

14 Frongia C, Lorenzo C, Gianni F, Prevost GP, Ducommun B, Lobjois V. 3D imaging of the response to CDC25 inhibition in multicellular spheroids. Cancer Biol Ther 2009; 8: $2230-2236$.

15 Herrmann H, Bär H, Kreplak L, Strelkov SV, Aebi U. Intermediate filaments: from cell architecture to nanomechanics. Nat Rev Mol Cell Biol 2007; 8: 562-573.

16 Wang J, Chen H, Seth A, McCulloch CA. Mechanical force regulation of myofibroblast differentiation in cardiac fibroblasts. Am J Physiol Heart Circ Physiol 2003; 285: H1871-H1881.

17 Kyrylkova K, Kyryachenko S, Leid M, Kioussi C. Detection of apoptosis by TUNEL assay. Methods Mol Biol 2012; 887: 41-47.

18 Räsänen K, Virtanen I, Salmenperä P, Grenman R, Vaheri A. Differences in the nemosis response of normal and cancer-associated fibroblasts from patients with oral squamous cell carcinoma. PLoS ONE 2009; 4: e6879.

19 Arcucci A, Ruocco MR, Granato G, Sacco AM, Montagnani S. Cancer: an oxidative crosstalk between solid tumor cells and cancer associated fibroblasts. Biomed Res Int 2016; 2016: 4502846.

20 Räsänen K, Vaheri A. Proliferation and motility of $\mathrm{HaCaT}$ keratinocyte derivatives is enhanced by fibroblast nemosis. Exp Cell Res 2010; 316: 1739-1747.

21 Guo Y, Xie J, Rubin E, Tang YX, Lin F, Zi X et al. Frzb, a secreted Wnt antagonist, decreases growth and invasiveness of fibrosarcoma cells associated with inhibition of Met signaling. Cancer Res 2008; 68: 3350-3360.

22 Santiago JJ, Dangerfield AL, Rattan SG, Bathe KL, Cunnington RH, Raizman JE et al. Cardiac fibroblast to myofibroblast differentiation in vivo and in vitro: expression of focal adhesion components in neonatal and adult rat ventricular myofibroblasts. Dev Dyn 2010; 239: 1573-1584.

23 lyer VR, Eisen MB, Ross DT, Schuler G, Moore T, Lee JC et al. The transcriptional program in the response of human fibroblasts to serum. Science 1999; 283: 83-87.

24 Wu K, Cheng HH, Chang TC. 5-methoxyndole metabolites of L-tryptophan: control of COX-2 expression, inflammation and tumorigenesis. J Biomed Sci 2014; 21: 17 .

25 Hinz B, Phan SH, Thannickal VJ, Prunotto M, Desmoulière A, Varga J et al. Recent developments in myofibroblast biology: paradigms for connective tissue remodelling. Am J Pathol 2012; 180: 1340-1355.

26 Katoh K, Kano Y, Masuda M, Onishi H, Fujiwara K. Isolation and contraction of the stress fiber. Mol Biol Cell 1998; 9: 1919-1938.

27 Esue O, Carson AA, Tseng Y, Wirtz D. A direct interaction between actin and vimentin filaments mediated by the tail domain of vimentin. J Biol Chem 2006; 281: 30393-30399.

28 Matsumoto K, Nakamura T. Hepatocyte growth factor and the Met system as a mediator of tumor-stromal interactions. Int J Cancer 2006; 119: 477-483.

29 Scholzen T, Gerdes J. The Ki-67 protein: from the known and the unknown. J Cell Physiol 2000; 182: 311-322.

30 Darby IA, Laverdet B, Bonté $F$, Desmoulière A. Fibroblasts and myofibroblasts in wound healing. Clin Cosmet Investig Dermatol 2014; 7: 301-311.

31 Desmouliere A, Redard M, Darby I, Gabbiani G. Apoptosis mediates the decrease in cellularity during the transition between granulation tissue and scar. Am J Pathol 1995; 146: 56-66.

32 Darby IA, Zakuan N, Billet F, Desmoulière A. The myofibroblast, a key cell in normal and pathological tissue repair. Cell Mol Life Sci 2016; 73: 1145-1157.

33 Kisseleva T, Cong M, Paik Y, Scholten D, Jiang C, Benner C. Myofibroblasts revert to an inactive phenotype during regression of liver fibrosis. Proc Natl Acad Sci USA 2012; 109: 9448-9453.

34 Rickham PP. Human experimentations, Code of ethics of the World Medical Association, Declaration of Helsinki. Br Med J 1964; 2: 177.

35 Mascia A, Gentile F, Izzo A, Mollo N, De Luca M, Bucci C et al. Rab7 regulates CDH1 endocytosis, circular dorsal ruffles genesis and thyroglobulin internalization in a thyroid cell line. J Cell Physiol 2016; 231: 1695-1708.

36 Bradford MM. A rapid and sensitive method for the quantitation of microgram quantities of protein utilizing the principle of protein-dye binding. Anal Biochem 1976; 72: 248-254.

\section{(c) (i)} article are included in the article's Creative Commons license, unless indicated otherwise in the credit line; if the material is not included under the Creative Commons license, users will need to obtain permission from the license holder to reproduce the material. To view a copy of this license, visit http://creativecommons.org/licenses/ by/4.0/

(c) The Author(s) 2017 